THE SAFETY CHALLENGE OF INCREASED CYCLING

\author{
Jack Short and Brian Caulfield ${ }^{1}$
}

Department of Civil, Structural and Environmental Engineering, Trinity College

Dublin, Dublin 2, Ireland

1. Brian Caulfield: Tel +353 1896 2534; Email: brian.caulfield@tcd.ie 


\title{
THE SAFETY CHALLENGE OF INCREASED CYCLING
}

\begin{abstract}
Many countries have recently set out policy frameworks to support the growth of cycling. However, increased cycling can mean more collisions, injuries and even fatalities. This paper discusses the role of safety in cycling policy in the particular case of Ireland, which is one of the countries that has a government-endorsed policy to increase cycling. It examines available information on cycling, including police-reported accident data over the last fifteen years and more recent hospital accident data. Comparisons are made for injuries between the two sources and data matching and capture-recapture methods used to estimate injuries. The deficiencies in data are analysed and suggestions for improvements made. It is argued that gaps in available data have led to accident risks being poorly understood. The paper discusses how a convergence in cycling and safety policy can be achieved and suggests additional measures including a cycling safety target, increased communication on cycling safety, lower urban speeds and compulsory wearing of helmets for children.
\end{abstract}

\section{Background: Road Safety and Cycling in Ireland}

\section{Road safety}

Ireland has had a highly successful decade in reducing road traffic fatalities and has jumped up the international safety league tables (International Transport Forum( IRTAD), 2011). Not previously known as a country with a particularly good road safety record, the achievements, especially in the latter half of the past decade have attracted a lot of attention from international bodies and from countries keen to understand the reasons for the improvements. With a fatality rate of less than 50 per million people, Ireland, in 2010, joined the elite group of around ten countries achieving this level (IRTAD, 2011). In terms of fatalities per vehicle kilometre, arguably a more correct measure, Ireland was rated fourth behind Iceland, Sweden and Great Britain, recording fewer than 5 deaths per billion vehicle kilometres. Cyclist fatalities have also fallen significantly and at 5 in 2010 were among the lowest (absolutely and per capita) in the OECD (IRTAD, 2011).

\section{Cycling}

Between 1986 and 2002, cycling in Ireland declined dramatically as can be seen from Table 1. The number of people cycling to work almost halved and, because the number at work grew, the modal share by bike fell from 5.6\% to below 2\% (CSO 2011(a)). The decline in cycling to school or college was even more striking. Between 1986 and 2006, the number of children between 5 and 12 years of age cycling to school fell by $83 \%$. The number of $13-18$ year olds cycling to school fell even more, by $85 \%$ and the number of girls of this age cycling to school 
fell by $98 \%$. In 2011 , there were as many people in this age group driving a car to school or college as there were cycling. (CSO, 2011 (a)).

The decline halted between 2002 and 2006 and cycling started to grow again. Supported by policy, including a successful scheme to subsidise bicycle purchase through tax-free loans (Caulfield and Leahy, 2011), the creation of cycleways and, probably also since 2008, by the severe downturn, there has been a significant increase in cycling, especially in Dublin, which introduced a city bicycle rental scheme, Dublin Bike, in September 2009. Since it began the scheme has accounted for over 5 million trips and cycling in the capital is now believed to account for $5 \%$ of city centre trips. (Caulfield et al, 2012). The Dublin Bikes scheme consists of 950 bicycles that can be rented from any one of 58 stations in Dublin City Centre (Dublin Bikes, 2014).

The growth of cycling has been reported in many studies (Busch-Geertsema and Lanzendorf, 2012; Caulfield, 2013; Pucher et al, 2011a, and Pucher et al, 2011b). This growth has been supported by national policy in many countries (ECMT 2004; ITF 2013). While many authors have examined the health and environmental benefits of a growth in cycling numbers, fewer have analysed what this increase means for road safety. In Ireland, while the number of cycling fatalities has been reduced significantly, the number of collisions and injuries has not declined and has even increased in recent years. International data (ITF, 2013. Figure 3.6) show that there are quite a few countries where, between 2000 and 2009, cycling collisions either increased (Germany, Switzerland, Belgium) or decreased at a slower rate than for other road users (US, Portugal, Canada, UK, Japan, Austria, France, Netherlands, Greece). Thus, managing safety in the context of a growth in cycling is a challenge in many countries.

\section{Data and Methods.}

\subsection{Cycling data}

Like many other countries, Ireland has limited data on the amount of cycling. The absence of such exposure data implies that there are no indicators on accident rates (per kilometre, per hour or per cyclist). As a consequence the absolute figures - the total number of fatalities or injuries- are those that are known and, therefore, most relevant for policy.

There are some data, however. The Census has collected information on cycling to work or school since 1986 (CSO, 2011(a)) and the first National Travel Survey in 2009 provides estimates on cycling by those over 18 (CSO 2011(b)).

These sources were combined to estimate the total amount of cycling in Ireland. The calculations are set out in Annex 1 and give an estimate of around 235 million bicycle kilometres per annum. Based on this estimate and the figure of 25 fatalities in the three years 2008-2010, one can derive a figure for Ireland of about 3.5 deaths per 100 million $\mathrm{km}$ cycled. This puts Ireland well behind leading cycling countries like Denmark and the Netherlands, somewhat behind France and Germany but close to the UK and US (Pucher and Buehler, 2012; ITF, 2013). Comparing this calculation with a similar one for motorised vehicles, we see that cycling fatality risk per kilometre in Ireland is about 8 times that of vehicle users. 


\subsection{Cyclist Accident data}

There are two main sources of information on cyclist accidents. These are, as in many countries, police reported collisions and hospital discharge data. There are other potential sources, like Accident and Emergency Units, Ambulance services, Injuries Board or Insurance data. But none of these has national data and the paper therefore focuses on the two principal sources.

\section{Police data}

The information which follows is derived from the Irish Road Safety Authority (RSA) database, which contains all police reported collisions from 1996 to 2010. There are over 102,000 collisions in the data base, of which over 6,000 involve a cyclist (Road Safety Authority, Road Collision Facts, various years). These are the official data on cycling accidents, as well as being the most widely known and the base for policy analysis.

The database is an invaluable source of information on collisions, and potentially an indispensible tool in helping to understand the reasons they occur and in taking action to avoid them. However, the database has a number of problems in relation to the quality of the data collected. Relevant data fields are poorly or ambiguously answered. There are no specific questions on cyclists' equipment e.g. whether a light was used or a helmet or high visibility clothing was worn and the details of the collision and the factors that contributed to it are limited. Given the increased policy importance being attached to cycling, it will be beneficial if an effort is made to improve the amount and quality of the information collected on cycling collisions. There are a number of steps in this regard that could be taken, including tidying up coding ambiguities and adding some questions on cyclists.

A particular problem, common to many countries (ITF 2012), is in the definition and measurement of a serious injury. The police in Ireland define a serious injury to include all those admitted to hospital as well as a set of other injuries ${ }^{1}$. This is the same definition as UK and New Zealand, but, as will be shown is not applied in practice, is unreliable as a measure of severity and is not consistent over time .

\section{Hospital data}

Hospital discharge data contains valuable information on the type of accident as well as being the only source for clinical data on the injuries. The hospital record dataset, known as the Hospital In-Patient Enquiry (HIPE) is collected from Ireland's acute hospitals and is managed by the Economic and Social Research Centre for the Health Service Executive. It covers admissions to all acute public hospitals in Ireland, where virtually all the emergency admissions go (HIPE , 2011).

1. The definition of "serious injury" is.. "an injury for which the person is detained in hospital as an "inpatient', or any of the following injuries whether or not detained in hospital: fractures, concussion, internal injuries, crushings, severe cuts and lacerations, severe general shock requiring medical treatment." 
The information includes details on the type of transport accident and clinical coding for injuries using the International Classification of Diseases (ICD) (WHO, ICD, $10^{\text {th }}$ edition 1990, Australian modification) and comparable information is available since 2005. The hospital data covers episodes of care and because there are no unique personal identifiers it is not possible to combine episodes into a personal record. If an injured person is transferred to another hospital, this will show as a second episode of care. This means that using episodes of care overstates the number of people involved. Estimates of return visits to hospital for the same injury can be made only in statistical terms. When this is done and matches made for age, sex, residence, principal diagnosis and type of accident, about $5 \%$ are seen to be repeat visits. Relaxing these conditions obviously increases the proportion but even with weak criteria the figure does not go above $10 \%$. Therefore, while the results shown in this paper are subject to error due to duplicate episodes of care, the error is unlikely to be greater than $10 \%$.

A second statistical issue concerns the nature of the accident. The ICD coding makes a distinction between a traffic accident and a non-traffic accident. A traffic accident is one that occurs on the public highway and that therefore could appear in the police reported data. For example, accidents on mountain bike routes or falls or collisions that occur in parks or driveways are not counted as road accidents by the Police. The ICD classification tries to reflect this idea in its coding. However, in Ireland almost two thirds of cyclist hospitalisations are categorised as non-traffic accidents. This is far higher than UK (Ministry of Transport UK, 2012) and an examination of the codes concerned leaves room for doubt on the accuracy of the coding. Take for example, the ICD codes V180 to V182. V180 is the code for cycle riders in non- traffic accidents, V181 for cycle passengers in non- traffic accidents and V182 is for unspecified cyclists in non- traffic accidents. Code V182 has over 1500 cases and it seems strange that coders are unsure whether the person was a cyclist or a passenger but were sure that it was not a traffic accident. Since the ICD coding instructions indicate that the default option is a traffic accident, this issue could merit a coding review at hospital level. Because of this, distinctions between traffic and non-traffic accidents are made where needed.

\subsection{Analytic Methods used}

The main analysis relies on statistical tabulations and comparisons from the police and hospital data bases to highlight the main trends and key points. In addition, binary logistic analysis, data matching and capture -recapture estimation were used to provide further insights into the data.

\section{Binary logistic models}

Logistic regression is the most important model for categorical response data and is used in a wide variety of applications. (Agresti, 2013) The models here are used to try to increase understanding of the factors influencing accident severity. The models take the following form: 


$$
\operatorname{logit}(\mathrm{p})=\log \frac{p}{1-p}=a+\beta I+e
$$

where $p$ is the probability of a severe accident, $l$ is the set of variables associated with the accident, the $\beta$ are coefficients and $\mathrm{e}$ is a random error term. The benefit from modelling is that the models provide more explicit indications on the nature and strengths of the relationships between severity and the factor concerned. The $\beta$ coefficients in the logit model indicate the change in the log odds ratio for a unit change in the independent variable. The values of $\operatorname{Exp} \beta$ give the odds ratios and are usually used, as they are easier to interpret.

\section{Data matching}

Comparing police and hospital data provides insights into the structure and composition of the two data sets. But it does not tell us whether they contain the same people or not. To do this the technique known as record linkage or record matching is used. The technique is increasingly used in public health and epidemiology and allows analyses that would otherwise be impossible or extremely expensive. It combines ideas from statistics, computer systems and operations research and has been greatly facilitated by high speed computing though it began earlier. A comprehensive overview is provided by Clark (2004) and there is an extensive literature review in ITF (2012).

Its use in road safety research is relatively recent. It has been used to make estimates of underreporting of particular kinds of accidents or injuries, as in the Rhone region in France by Amoros et al (2007). It has allowed comparison of information on the medical consequences of accidents using the established ICD injury codes for hospital data combined with the on the spot assessment by the police. It is being used to estimate costs, to identify associated factors in collisions and to estimate the number of severe casualties. For example, the UK now uses the method to recalculate the social costs of crashes (Department for Transport, UK, 2012) and New Zealand uses it as a benchmark for the police as well as in the calculation of social costs. The International Transport Forum (ITF 2012) cites 16 countries where the technique has been used in road safety. Despite its limitations, it can contribute to a better understanding of the injury problem. In addition, the combination of information from police and hospitals is a valuable research resource on crashes and their consequences.

The terms "deterministic", "fuzzy" or "probabilistic" are used to describe the different kinds of record linkage or data matching. Deterministic matching is where matches can be found directly by examination of the records using unique identifiers. Fuzzy matching is where scores are assigned for matches on different variables and the scores totalled to give a matching score. Probabilistic matching uses the mathematical theory developed by Felligi and Sunter (1969) to assign pairs as matched or unmatched or undecided. A mixture of fuzzy and probabilistic matching is used here. Neither the police nor hospital data in Ireland have any personal identifiers and matching is done on the basis of five variables, date of crash and hospital admission, age, sex, mode and County. In international terms, the data available for matching in Ireland are weaker than in those countries with unique identifiers like Denmark, Finland, Sweden and Switzerland, but also than those which have good crash localisation and hospital information like Japan, Netherlands, the UK and Spain. Ireland has 
strong data privacy and patient protection laws and the data available for matching seem more similar to countries like Austria and Germany (ITF 2012). This means that matching will inevitably be less accurate than in countries with more precise matching variables. Before the data matching can be carried out there is a significant amount of data preparation to be undertaken as well as decisions on the weightings and methods to be used to be used. They are set out in more detail in the literature, for example in Amoros et al (2007), and in this case, in Short (2013).

\section{Capture - Recapture}

The capture-recapture method has been used mainly in animal zoology, in order to estimate a population size. This has led to an extensive literature with increasingly sophisticated statistical methodologies. These are well summarised in a handbook edited by Amstrup and others (Amstrup, 2005). Capture -recapture is increasingly being used in other fields, including demography and health, in the estimation of the prevalence of medical conditions and the size of hidden populations like drug users.

It has been applied more recently to road traffic injury, usually focusing on subgroups, such as children or teenagers, cyclists or truck drivers. ITF(2012) has a bibliography. Specific examples of the use of the method in road safety are Razzak (1998), Jarvis (2000), Morrison and Stone(2000) and Amoros (2007).

The easiest case is when there are two "captures" or, for human populations, lists or registrations or data sets. Here the basic principle is elegantly simple. If, the two lists $A$ and $B$, contain $\mathrm{N}_{\mathrm{A}}$ and $\mathrm{N}_{\mathrm{B}}$ individuals with $\mathrm{n}$ common to both lists, an estimator (known as the Lincoln-Petersen estimator) of the true population size $N$ is given by $N_{A} N_{B} / n$. The reasoning is that the proportion recaptured in the second sample is representative of the entire population and so $\mathrm{N}_{\mathrm{A}} / \mathrm{N}=\mathrm{n} / \mathrm{N}_{\mathrm{B}}$.

This estimator is unbiased with other desirable statistical properties under specific conditions. The relevant ones here are, (see Hook and Regal (1999) exact identification of subjects common to both registrations, independence between the registrations and homogeneity of capture by a given registration. None of these are fully met for police and hospital data and the results should at this stage be seen as indicative. Further work to improve the estimates requires more precise matching variables, a deeper understanding of the associations between the data sets, and indications from other sources like Accident and Emergency.

\section{Analysis of data}

\subsection{Police reported cycle accidents}

This section of the paper uses information from the road safety database to provide a broad picture of cycling collisions in Ireland. Much of the information is contained in Tables A1 and $A 2$ in the Annex. 
From these data we would like to focus on two main points. The first concerns the relative frequency of cycling collisions compared to all traffic collisions. The data show the circumstances where there is a higher share of cyclist collisions than general collisions. These include weekdays, the summer months, fine weather and peak traffic times. These findings are similar to those in other countries (ITF, 2013; De Geus, et al, 2012; Knowles, et al, 2009). The higher accident frequencies under these circumstances are likely to be linked to the higher volumes of cycling traffic under these conditions. In the same way, three quarters of the casualties are men but this too reflects the fact that around three times as many kilometres are cycled by men. There is one clear exception and it is the proportion of cyclist collisions that occur at junctions. A half of cyclist collisions occur there, obviously greater than the share of kilometres or time spent at them. This finding is also confirmed in the literature referenced above and is a particular concern for cycling policy.

Secondly, the data underline and quantify the vulnerability of cyclists. In collisions involving cyclists, it is the cyclist that is killed or injured in $97.5 \%$ of the cases. This equates to the cyclists being 40 times more likely to be killed or injured in a collision than the occupants of the other vehicle. In addition, the risk per kilometre of being involved in a fatal collision is 8 times higher for cyclists (see Annex 1 for the calculation). The higher risk of being in an accident and the much higher risk of injury or death in a collision, are central to considering the safety of cyclists.

\subsubsection{Analysis of police data on severity}

Defining and measuring accident severity is problematic and different definitions can give quite different results (ITF, 2012). The one used officially in Ireland is the police assessment on the spot. Table A3 in the Annex shows how collision severity, as assessed by the police, varies under different circumstances. The table shows how serious accidents occur under all the identified circumstances. However, it also shows how some particular circumstances are associated with significantly higher serious injury rates. These are dark roads at night, collisions that are not at junctions, being unfamiliar with the location, higher speed limits and being under 14 or over 65 years of age. In fact, cyclist age and accident severity are related in a $U$ curve with peaks at the youngest and oldest ages.

Speed and severity are linked in a strikingly clear way with accident severity increasing rapidly with speed, as a glance at Table $\mathrm{A} 2$ will confirm. That only $5 \%$ of collisions are severe in $30 \mathrm{~km} /$ hour zones contrasts with the growing figure as the speed limit increases and especially with the figure of $37 \%$ for the $100 \mathrm{~km}$ speed limit.

An important conclusion for policy concerns the fact that severe accidents happen under all circumstances. From this it can be inferred that, while specific measures targeted at particular circumstances could reduce severity, doing so across all conditions requires more general measures, which would apply universally. And, from the evidence presented in Tables $A 2$ and $A 3$, speed is a key factor influencing collision severity and is therefore a main policy variable on which to act. 


\section{Logit Regression Analysis}

The cycling accident data above, with records of over 6000 collisions from 1996 to 2010 was analysed to see if further insights could be obtained on the relationships between police recorded severity and possible explanatory factors. For this a series of logit regression models were estimated. As before, possible explanatory factors were classified into two groups, personal and trip factors and road and conditions factors. In the first group were age and sex as well as time of day, day of the week and month of collision, trip purpose and whether the person was familiar with the location. In the second, the factors were light(whether in daylight or at night), the weather, road surface conditions road type characteristics and markings, junction type and type of collision. Other studies have used this approach to analyse the severity of cyclist accidents for example Moore et al, (2011), Kim et al (2011).

The variables included in the model selected are described in Annex Table A4 while Table 4 summarises the results. As suggested in the descriptive analysis above, several of the variables examined had no significant influence on the severity of the collision; and this was confirmed by the non-significance of the $\beta$ values for these variables.

For police-recorded serious crashes, and considering first the group of variables concerned with person and trip factors, there was no difference in severity by gender, nor by when the collision occurred or trip purpose. However, as shown also in Table A3, age is an important exception and severity was higher for the oldest and youngest age groups. The Exp $\beta$ coefficients indicate that the severity odds ratio almost doubles for cyclists aged under 14 and those over 55. A significant $\beta$ coefficient was found also for young male drivers of the motorised vehicle involved in the collision.

In the road and conditions factors, there was no difference in the severity in different weather conditions or in different road surface conditions. The factors that made a difference were unlit roads at night and speed. For dark roads at night, the odds ratio increases by a factor of over 2 . For speed, the figure of 1.033 for the odds ratio indicates a $3 \%$ increase in the odds of being seriously injured for every $\mathrm{km} /$ hour increase in speed. This finding accords well with the literature and in particular with what is known as Nilssons power law (Nilsson, 2004).

In summary, the logit analysis confirms the significance of the factors shown in Table A3. In addition, it provides estimates of how the odds of a serious injury change as the explanatory factors change.

While these insights are interesting and that on speed is highly relevant for policy, it is important to note that the logit models are not good predictors of serious collisions. This is mainly because the majority of collisions occur in "normal" conditions and the variables associated with higher risk in the model occur relatively infrequently. It is also because variables that might better explain severity are not available. Such variables are used in other cycling studies e.g. Kim and Moore already cited, and include speed at impact, point of 
impact, whether the cyclist or driver had been drinking and whether the cyclist had a light or wore a helmet or high visibility clothing.

\subsection{Hospital In-patient data}

The following summary is based mainly on the material in Tables 3 and 4 and Tables A5 to A7 in the Annex.

In the period 2005 to 2011, hospitals recorded 6,565 emergency in-patient episodes of care for cyclists. Of these 2,304 (35\%) were recorded as traffic injuries. The remaining $65 \%$ were mainly falls and were recorded as non-traffic accidents or were unspecified. Less than $10 \%$ of the episodes were coded as traffic accidents involving a collision with a vehicle. The share of episodes classified as traffic or transport is stable over time.

Over this period, cyclist injuries accounted for over 19,000 days in hospital. The trend is increasing and the number of days spent by cyclists in hospital is a growing share of the total days spent in hospital by transport casualties. In 2011, cyclists accounted for $13.9 \%$ of the days spent in hospital from transport injuries- up from $8.3 \%$ in 2005 , as shown in Table3.

Almost three quarters of the episodes concern males (73\% to $27 \%$ ). This differs slightly for traffic accidents, which has $76 \%$ males. This proportion varies by age group with males accounting for $85 \%$ of the episodes in the 15-24 age group. Importantly, $55 \%$ of those admitted are under 15 years of age. Head injuries account for almost $40 \%$ of hospital admissions, well ahead of arm and elbow injuries, which account for about $20 \%$.

One measure of severity is length of stay in hospital. The data show that $22 \%$ of in-patients are released on the same day and $62 \%$ stay one day or less. Stays of four days or more accounted for 956 (15\%) episodes and of six days or more for 584 (9\%). The average length of stay is around 3 days and the median is 1 day. Work is underway to apply clinically based classifications like the Abbreviated Injury Scale (AIS) to Irish Hospital data but they are not available for this analysis.

\subsection{Comparison of Police and Hospital data sets}

The two data sets are compiled for different purposes and in different ways. Both are subsets of those injured in bicycle accidents, with one limited to cases where the police were called and the other to emergency in-patient episodes in hospital. The next section compares the two data sets directly.

\subsubsection{Direct comparisons}

Table 4 summarises the police and hospital data for the years from 2005 to 2011. Police recorded 2,133 cycling injuries, 2,000 minor and 133 serious ones. Hospitals had 6,565 episodes of care for cyclists. So hospital data shows roughly three times as many incidents involving cyclists as the police data even allowing for repeat care episodes. However, the coding of the hospital episodes indicates that only that 2,304 (35\%) were traffic accidents. 
The remaining $65 \%$ of accidents coded as non- traffic or transport accidents are mainly falls of which there are around 4,000.

The figure of 2,304 traffic accident episodes from the hospital data is at first sight comparable with the 2,133 police collisions. But, though the numbers are similar the people involved are not necessarily the same. For example, hospitals record 589 episodes involving a collision with a vehicle (car, van, truck and coded V12-V16 in the ICD). The police recorded 1,845 injuries involving a collision with a car and 187 with a truck. So police data show over three times as many collision related injuries as the hospital data.

Both datasets show a predominance of males in the accident figures. The police data show that $76 \%$ of those injured were males and the hospital data shows $73 \%$ of the episodes involved males.

In contrast, the age structure of the data sets is strikingly different. Over $55 \%$ of those admitted to hospital were under 15 . And for hospitalised females, the figure is $63 \%$. The share of police recorded cyclist injuries that are under 15 is only $14 \%$.

The cyclist data from both sources show a picture that is at odds with the broader data on road accidents. Neither police recorded injuries nor days spent in hospital by cyclists are declining as they are for all other modes. As a result, the share of total road traffic injuries accounted for by cyclists is increasing. In 2011, cyclists accounted for $14 \%$ of the days spent in hospital in all transport accidents, far in excess of the $0.6 \%$ of vehicle kilometres that cyclists account for (CSO,2011(a) and (b), also Appendix1).

The police data indicate a large decline in the share of injuries that are serious from $11 \%$ in 2005 to $4 \%$ in 2011. This decline can be an accurate gauge of a real reduction in accident severity or can also reflect administrative and other factors. The police assessment is obviously not a clinical assessment and can be influenced by, among other things, the work police have to carry out if an injury is judged to be serious.

Different measures of severity can also be obtained from the hospital data. Clinical coding of the injuries has not yet been translated into the recognised classifications like AIS or ICISS. Ireland has committed to moving to MAIS but the coding work has not yet been undertaken. Here, length of stay (LOS) has been used as a proxy for seriousness of injuries. While it is an imperfect measure, being subject to administrative or supply side influences it does give useful indications. The data show that LOS for cyclists is relatively stable with an average of 3 days and a median of 1 day. Length of stay for collisions with another vehicle shows higher averages and variances. On this measure, hospital data does not indicate a decline in the severity of cycle accidents.

The data in Table 4 updates and expands on the work of Bedford et al (2011). Bedford (2011) argued that the comparison of hospital and police data showed how police data understated the number of serious injuries. For cyclists, this understatement was greater than for other modes. The analysis here confirms that the number of hospitalised cyclists far exceeds -by a factor of almost 50- the number of cyclists reported as seriously injured by the police. The findings here compare also police- reported minor injuries with hospital 
data and show that, unlike other modes, the number of hospitalised cyclists exceeds also the police reported number of minor injuries (Short (2013)). Moreover, the data confirm that the police frequently misclassify a serious injury as a minor one (by definition, any person admitted to hospital as an in-patient is seriously injured). This shows that the police do not apply their own definition of serious injury and further, the evidence suggests that the police classification of a serious injury has changed over time. In conclusion, the data here show that the cyclist collision problem is both greater and more complicated than thought previously.

\subsubsection{Matching Police and Hospital data}

The matching was carried out for the police file of 2,133 injuries and a hospital file with 3,158 care episodes, including all the traffic accidents as well as some of the other cases where there is uncertainty on whether the episode related to a traffic accident or not.

Matching was carried out with different thresholds and scoring systems and levels of posterior probability. Using a posterior probability ( the probability of a true match given agreement on matching variables) of .85 the number of matches was $571,18 \%$ of the hospital records and $27 \%$ of the police file. These figures can be used, on certain assumptions, to make estimates of the total number of cycling injuries in traffic accidents using what is known as the capture - recapture method. This is done in the next section.

To summarise, the matching shows that about half the police reported seriously injured cyclists were matched with hospital records. Of the police reported seriously injured cyclists that were matched, $30 \%$ remained in hospital for a day or less. On the other hand, around $10 \%$ of the matched cyclists with minor injuries remained in hospital for more than four days. When matches are found for police reported serious injuries there is a tendency for them to be longer stay patients. But police reported serious injuries are also found among short stay patients and about half do not seem to get to hospital at all. This underlines the obvious point that police recorded serious injury is not a reliable indicator of severity but more significantly, emphasises that the two groups do not overlap to a large extent. This leads then to the following attempt to estimate the true number of injured cyclists.

\subsubsection{Capture-recapture estimates}

As mentioned in section2, capture recapture can be used to estimate population size based on a number of samples or registrations. With two samples, the Lincoln-Petersen estimator is unbiased if there is independence between the samples, perfect identification of the common individuals and homogeneity of the probabilities of being in each data set. These conditions are not met for these data and the estimate is indicative only.

Using the Lincoln_Petersen estimator, the number of cyclist traffic injuries would be $2133 * 3158 / 571=11,796$, which is six times the police reported number and twice the total number hospitalised.

While the calculation is approximative, it can safely be concluded that the cyclist injury problem is both much greater and different in structure than the official figures indicate. The final section of the paper examines the implications for policy of these findings. 


\section{Can Safety and Cycling Policy converge?}

The data presented above for Ireland seem to conform to the situation in many countries, with limited exposure data, under reporting of collisions, and poor or missing collision information (ITF, 2013). From the evidence presented above, the official data on cycling safety do not correctly reflect the risks or vulnerabilities of cyclists. Per kilometre travelled cyclists are 8 times more likely to have a fatal collision, and 40 times more likely to be injured or killed in a collision. Moreover many injuries are not included in official statistics and neither police nor hospital data fully captures the extent of the accident problem in cycling.

The evidence above points to some clear directions for policy as it attempts to reconcile the broadly environmental aims of cycling policy with the safety objective to make cycling a low risk transport option.

Safer pro-cycling policies will start with a more careful collection and organisation of the crash data. There is a need for a better understanding of the real extent of the cyclist crash problem. This requires both better collision data and improved exposure measures. Police data needs to include more and better information on cyclist accidents. Hospital data, not widely used up to now, should become a regular source of information, to complement and verify police data and also for clinical data for analysis on injuries. Both sources are relevant for transport and health policy and provide different perspectives on the problem. The national travel survey needs larger samples to provide more reliable exposure data for cyclists. The large number of non-collision accidents, mainly falls, many involving children, frequently have serious consequences and little is known of them. Finally, it is essential to learn from cycling collisions through detailed study of crashes. This information should be available for research.

The data since 2005 shows an increase in reported collisions and in the number of hospitalisations. Cycling is growing but because the data on this are not precise it is not possible to say if collision and injury rates are declining. There is a developing literature on "safety in numbers" which tries to identify a mechanism that might explain declining accident rates as traffic grows (Johanssen, 2003; Elvik, 2009; Wegman, 2012 and ITF, 2013). It will be useful to begin such analysis in Ireland. But as exposure data are not available for cycling and as all other categories of road traffic casualties are declining in absolute terms, it cannot be claimed that the cycling policy is a success. Cycling is about 8 times more risky than car driving per kilometre. As a result, encouraging people out of cars (or public transport) on to bicycles increases the risks and, other things equal, will lead to an increase in the number of collisions. The stated aim to increase cycling by a factor of four by around 2020 will therefore see a large increase in the number of accidents unless there is a commensurate reduction in per kilometre risk. Even if cycling grows at a lower rate (which seems more plausible), a reduction in risk per kilometre of the same order would be required to maintain a stable number of accidents. It does seem reasonable that, in the absence of more precise exposure measures, an objective that the number of cyclist casualties would not increase, would be agreed to accompany the cycling volume target. And the measurement should be based on all sources not just police reported data. 
In addition, the severe asymmetry in collision consequences needs to be more central to policy. The chances of minor injury, serious injury or death in a collision are 40 times higher for a cyclist. This justifies additional measures both to avoid the likelihood of collisions and to minimise their consequences. For each, the most important factor is vehicle speed.

Urban speed limits are generally set at $50 \mathrm{~km} /$ hour. Moreover, the $50 \mathrm{~km} /$ hour speed limits are those where respect of the limits is least. Surveys show that $59 \%$ of cars on urban roads are speeding (RSA, 2012). If this infrastructure is to be shared with cyclists this is too fast. Since 2010, there has been an increase in the number of roads with $30 \mathrm{~km} /$ hour limits. Based on the crash data, there is a strong case to extend this network significantly. Reductions in speed will reduce crash severity much more than proportionately. And the same argument applies also in rural areas where many of the serious collisions occur. Since speeding is so prevalent, the strengthening of speed enforcement seems also to be a rather obvious response.

Wearing helmets is not compulsory for cyclists in Ireland. This reflects long standing practice as well the views of many cycling organisations and supporters. The perception that the success of the Dublin Bike scheme is partially at least due to the fact that helmets are not compulsory is also a factor. However, the evidence above that a very large share of hospitalisations, especially among children, involve head injuries provides evidence that the compulsory wearing of helmets, initially by children, could have important health benefits.

Cycling advocates argue that putting too much accent on safety undermines the aim to encourage cycling and risks to put people off. On the other hand, the risks are real, have been understated and should not be ignored. And while cyclists are the losers in collisions, they also have responsibilities. The police data indicate that cyclists were at least partially responsible in about half the collisions. There is therefore scope to improve cyclist behaviour. For this, more information on risks, and practical advice and training on dealing with dangerous situations can contribute.

Finally, the data above and surveys of cyclists, for example (Lawson et al, 2012) show there is still a significant effort needed to improve cycling infrastructure, to increase separation from other vehicles, deal with cyclist safety at junctions and reduce risks in rural areas and at night.

\section{Conclusions}

Cycling is growing and is being supported by public policy. The evidence here shows that cycling is less safe than official figures show and that cycling is not becoming safer as other modes are. If cycling policy is to be successful, safety needs to be more at its centre. In the absence of exposure data safety targets could be set on the basis of no increase in the absolute numbers of victims. Better integration of cycling and safety policies requires additional efforts to improve the understanding of the safety problem for cyclists. Here both police and hospital data should be used and both need to be improved. The extreme 
vulnerability of cyclists in collisions justifies additional measures to protect them including more $30 \mathrm{~km} /$ hour speeds, and the wearing of helmets, at least by children.

\section{Acknowledgements}

The authors would like to thank the Road Safety Authority of Ireland for providing the collision data for this research and the Economic and Social Research Institute for the Hospital In Patient Inquiry (HIPE) data. 


\section{References}

Agresti, A. (2013). Categorical Data Analysis; Third Edition: Wiley.

Amoros E, Martin JL, Laumon B. Estimating non-fatal road casualties in a large French county, using the capture-recapture method. Accident Analysis and Prevention, 2007 May; 39(3):483-90.

Amstrup, S., C,Trent L Mc Donald, Bryan FJ Manly (editors). (2005). Handbook of CaptureRecapture Analysis; : Princeton Press.

Bedford, D., 2011,Sheridan, A., Howell, F., McKeown, N.,. Admission to Acute Hospitals for Injuries as a Result of Road Traffic Collisions in Ireland, 2005-2009.

Caulfield, B, The growth of cycling in Dublin City, World Conference on Transport Research, Rio de Janeiro, 2013

Caulfield, B., Brick, E., McCarthy, T.O. Determining bicycle infrastructure preferences - A case study of Dublin. Transportation Research Part D: Transport and the Environment, 17, 2012, 413-417.

Caulfield, B., Leahy, J., Learning to cycle again: examining the benefits of providing tax-free loans to purchase new bicycles, Research in Transportation Business \& Management, 2, 2011, pp $42-47$.

Central Statistics Office, Ireland (CSO) 2011 (a); Census Reports.

Central Statistics Office, Ireland (CSO) 2011 (b); National Travel Survey, 2009.

Clark DE. Practical introduction to record linkage for injury research. Injury Prevention 2004; 10(3):186-191.

de Geus, B., et al. "A prospective cohort study on minor accidents involving commuter cyclists in Belgium." Accident Analysis and Prevention 45 (2012): 683-693.

Department for Transport UK,. Linking Police and Hospital data on Road Accidents in Engand; 1999 to 2009; Feb, 2012.

Dublin Bikes. Accessed online. 12/2/2014: http://www.dublinbikes.ie/Stations/Viewstations/Dublinbikes-station-list

Elvik, R., "The non-linearity of risk and the promotion of environmentally sustainable transport." Accident Analysis and Prevention 41 no. 4 (2009); 849-855.

European Conference of Ministers of Transport (ECMT); National Policies to Promote Cycling, OECD, Paris 2004. 
[8] Fellegi, Ivan, Sunter, Alan (1969). "A Theory for Record Linkage". Journal of the American Statistical Association 64 (328): pp. 1183-1210.

Hospital In-Patient Enquiry (HIPE), Annual Report 2011. Accesible on line at http://www.esri.ie/ uuid/304e5d17-aa6e-4878-8437-8c8e6f9ef653/index.xml

International Transport Forum (2011) IRTAD, Road Safety Annual Report. OECD, Paris

International Transport Forum (2012) IRTAD. Reporting on Serious Road Traffic Casualties

International Transport Forum (2013); Cycling Safety OECD, Paris.

Jarvis SN, Lowe PJ, Avery A, Levene S, Cormack RM. Children are not goldfish-mark/recapture techniques and their application to injury data. Injury Prevention. 2000 Mar; $6(1): 46-50$.

Kim, J-K., Kim, S., Ulfarsson, G.F, Porrello, L.A., Bicyclist injury severities in bicycle-motor vehicle accidents. Accident Analysis and Prevention, 39, 2007, 238-251.

Knowles J, Adams S, Cuerden R, Savil T, Reid S, Tight M. Collisions involving pedal cyclists on Britain's roads: establishing the causes. PRR 445 TRL (2009)

Jacobsen, P.L. Safety in Numbers: more walkers and bicyclists, safer walking and bicycling. Injury Prevention 9, 2003, pp205-209

Lanzendorf, M., Busch-Geertsema, A. The Cycling Boom in Some German Cities: Understanding and Explaining Behavioural Change. The 13th International Conference on Travel Behaviour Research, Toronto, 2012.

Lawson, A.R., et al., Perception of safety of cyclists in Dublin City. Accident Analysis and Prevention, (2012), http://dx.doi.org/10.1016/j.aap.2012.05.029

Hook, E. B. and Regal, R. R., 1999. Recommendations for presentation and evaluation of capture-recapture estimates in epidemiology. Journal of Clinical Epidemiology 52 (10), 917926; discussion 929-933.

Ministry of Transport, Ireland; National Cycling Policy Framework, 2009.

Moore, D.N., Schneider, W.H., Savolainenb, P.T., Farzanehc, M., Mixed logit analysis of bicyclist injury severity resulting from motor vehicle crashes at intersection and nonintersection locations. Accident Analysis and Prevention, 43, 2011, 621-630.

Morrison A and Stone D, Capture-recapture: a useful methodological tool for counting traffic related injuries? Injury Prevention, 2000. 6(4)299-304. 
H.B. Newcombe, J.M. Kennedy, S. Axford, and A. James, Automatic Linkage of Vital Records, Science, vol. 130, no. 3381, pp. 954-959, ...

Pucher, J, Buehler, R, Making Cycling Irresistible: (2008) Lessons from The Netherlands, Denmark and Germany, Transport Reviews, 28:4, 495 - 528.

Pucher, J., Garrard, J., Greaves, S. Cycling down under: a comparative analysis of bicycling trends and policies in Sydney and Melbourne. Journal of Transport Geography 19 (2011a) 332-345.

Pucher, J., Buehler, R., Seiner, M. Bicycling renaissance in North America? An update and reappraisal of cycling trends and policies. Transportation Research Part A 45 (2011b) 451-475.

Pucher,J and Buehler,R (eds) City Cycling. MIT Press, 2012.

Razzak, J. A. and Luby, S. P., 1998. Estimating deaths and injuries due to road traffic accidents in Karachi, Pakistan, through the capture-recapture method. International Journal of Epidemiology 27, 866-870.

Road Safety Authority, Ireland Road Collision Facts, Various Years; Available on line at http://www.rsa.ie/en/RSA/Road-Safety/Our-Research/Collision-Statistics/

Road Safety Authority, Ireland (2012) Free Speed Survey 2011, March 2011.

Road Safety Authority, Ireland (2013) National Strategy for Safety to 2020; Closing the Gap.

Short, J., How many Road Collisions in Ireland, Irish Transport Research Network Conference, Sept 2013,

Wang, Y., Nihan, N. L . Estimating the risk of collisions between bicycles and motor vehicles at signalized intersections. Accident Analysis and Prevention, 36, 2004, Pages 313-321

Wegman, F., Zhang, F., Dijkstra, A., How to make more cycling good for road safety? Accident Analysis and Prevention, Volume 44, Issue 1, January 2012, Pages 19-29

World Health Organisation (WHO) International Classification of Diseases (ICD). $10^{\text {th }}$ edition, 1990 , available on line at http://apps.who.int/classifications/icd10/browse/2010/en 


\section{Annex 1}

\section{Estimate of Total Distance Cycled in Ireland}

Two sources are used, the national travel survey (CSO, 2011), carried out for the first time in 2009, and Census data (CSO various years), since 1986.

The national travel survey estimates are that the total number of cycling kilometres undertaken in the reference week was 3.36 million kilometres. This is calculated for all persons 18 years and over, on the basis of an average of 17 trips per person per week, an average trip distance of $5 \mathrm{~km}$ and an estimate of the share of trips by bicycle at $1 \%$. The population 18 years and over in 2009 is estimated to be 3.3 million. Putting these together gives the estimated total distance of 3.36 million kilometres above. Multiplying this by 52 is likely to give an underestimate of the total kilometres cycled as the week in question was in November and was exceptionally cold. On the other hand, there is no obvious adjustment factor to apply. The number of collisions in November is not much lower than other months and no particular reasons have been identified to indicate more risky behaviour in November. On balance, it has been decided to not adjust the weekly estimate. This gives a figure of 174.7 million kilometres per annum.

Census data (CSO,2011 (a)) provides estimates on travel to school and college by those under 18, information not collected in the National Travel Survey. . There were 6,252 students in the age range 5-12 cycling an average daily distance of $8 \mathrm{kms}$. Multiplying by 200 gives 10 million kms. Similarly for the 6,592 students aged $13-18$ cycling $16 \mathrm{kms}$ a day a total of 19.8 million $\mathrm{kms}$ is obtained. This gives a total of 29.8 million kilometres as the distance travelled to school. No information is available on other cycling activities by children. As a guess, this figure is doubled, giving an estimate of about 60 million kilometres cycled by children. Adding the figures from the two sources gives 235 million kilometres as an estimate of the total distance cycled annually in Ireland.

To calculate accident rates, total vehicle kilometres travelled in 2010 were 42,409 million kms (Road Traffic volumes data, Central Statistics Office, 2013) and the cycling share is therefore $235 / 42409=0.6 \%$. 


\section{TABLES}

\section{Tables for text.}

Table 1. Cycling to work, Ireland 1986-2011.

Table 2. Logistic Regression Results.

Table 3. Hospitalisation for Transport and Cycling injuries; 2005-2011.

Table 4. Comparisons of Hospital and Police Injury data.

Figure 1. Cyclist Collisions 1996-2010.

Figure 2. Cyclist Casualties 1996-2010.

\section{Annex Tables.}

Table A1. Trends in total and cyclist collisions - 1996-2010.

Table A2. All Collisions and Collisions Involving Cyclists, 1996-2010.

Table A3. Cycle Collision Severity.

Table A4. Logistic Regression; Definition of Variables included.

Table A5. Hospitalised Cyclists by type of accident and whether traffic or not 2005-2011.

Table A6. Length of Stay for Cyclists by type of accident, 2005-2011.

Table A7. Hospitalised Cyclists by Sex Age and Type of Injury 2005-2011. 
Tables and Figures to Include in Text

Table 2. Cycling to work, Ireland 1986-2011.

\begin{tabular}{|l|c|c|c|}
\hline Year & Number Cycling to Work (000) & Total at Work(000) & \% Cycling \\
\hline 1986 & 60.8 & 1,084 & 5.6 \\
\hline 1991 & 50.3 & 1,137 & 4.4 \\
\hline 1996 & 46.5 & 1,294, & 3.6 \\
\hline 2002 & 34.3 & 1,610, & 2.1 \\
\hline 2006 & 36.3 & 1,8923 & 1.9 \\
\hline 2011 & 39.8 & 1,695 & 2.3 \\
\hline
\end{tabular}

Table 2. Logistic Regression Results.

\begin{tabular}{|ll|r|r|r|r|r|r|}
\hline \multicolumn{2}{|c|}{ Variables in the Equation } & \multicolumn{1}{c|}{$\boldsymbol{\beta}$} & \multicolumn{1}{c|}{ S.E. } & \multicolumn{1}{c|}{ Wald } & \multicolumn{1}{c|}{ df } & \multicolumn{1}{c|}{ Sig. } & \multicolumn{1}{c|}{ Exp( $\boldsymbol{\beta})$} \\
\hline Serious & Speed & .032 & .002 & 268.542 & 1 & .000 & 1.033 \\
Collisions & Dark Roads & .798 & .191 & 17.531 & 1 & .000 & 2.222 \\
& Older Cyclists & .632 & .124 & 25.784 & 1 & .000 & 1.881 \\
& Young Cyclists & .556 & .101 & 30.178 & 1 & .000 & 1.743 \\
& Young Driver & .385 & .120 & 10.250 & 1 & .001 & 1.470 \\
& Constant & -4.156 & .131 & 999.374 & 1 & .000 & .016 \\
\hline
\end{tabular}


Table 3. Hospitalisation for Transport and Cycling injuries; 2005-2011.

\begin{tabular}{|l|c|c|c|}
\hline \multirow{2}{*}{ Year } & \multicolumn{2}{|c|}{ Hospital Days } & \multirow{2}{*}{ Cyclist Share } \\
\cline { 2 - 4 } & All Transport & Cyclists & \\
\hline 2005 & 34,028 & 2,818 & 8.3 \\
\hline 2006 & 34,988 & 2,764 & 7.9 \\
\hline 2007 & 32,159 & 2,651 & 8.2 \\
\hline 2008 & 33.544 & 2,710 & 8.1 \\
\hline 2009 & 27,694 & 2,820 & 10.2 \\
\hline 2010 & 24,318 & 2,558 & 10.5 \\
\hline 2011 & 20,105 & 2,794 & 13.9 \\
\hline
\end{tabular}

Source: HIPE data, ESRI

Table 4. Comparisons of Hospital and Police Injury data.

\begin{tabular}{|l|l|l|l|l|l|l|l|l|l|}
\hline Source & Type & $\mathbf{2 0 0 5}$ & $\mathbf{2 0 0 6}$ & $\mathbf{2 0 0 7}$ & $\mathbf{2 0 0 8}$ & $\mathbf{2 0 0 9}$ & $\mathbf{2 0 1 0}$ & $\mathbf{2 0 1 1}$ & Total \\
\hline Police & Serious & 24 & 18 & 19 & 27 & 21 & 13 & 16 & 133 \\
\cline { 2 - 10 } & Minor & 177 & 190 & 236 & 305 & 339 & 378 & 375 & 2000 \\
\hline $\begin{array}{l}\text { Hospitalised } \\
\text { (traffic accidents) }\end{array}$ & Total & 318 & 333 & 344 & 272 & 301 & 371 & 365 & 2304 \\
\cline { 2 - 10 } & $\begin{array}{l}\text { Over } \\
\text { one day }\end{array}$ & 136 & 120 & 155 & 121 & 124 & 166 & 164 & 986 \\
\hline $\begin{array}{l}\text { Over } \\
4 \text { days }\end{array}$ & 60 & 61 & 62 & 62 & 51 & 74 & 76 & 446 \\
\hline $\begin{array}{l}\text { Over } \\
\text { (All days }\end{array}$ & 44 & 37 & 35 & 41 & 34 & 42 & 50 & 283 \\
\hline & Total & 948 & 886 & 933 & 823 & 934 & 1032 & 1009 & 6565 \\
\cline { 2 - 10 } & Over 1 day & 372 & 312 & 396 & 313 & 332 & 384 & 393 & 2492 \\
\cline { 2 - 10 } & Over 4 days & 145 & 124 & 127 & 130 & 128 & 149 & 153 & 956 \\
\cline { 2 - 9 } & Over 6 days & 94 & 75 & 75 & 77 & 84 & 79 & 100 & 584 \\
\hline
\end{tabular}


Figure 1. Cyclist Collisions 1996-2010.

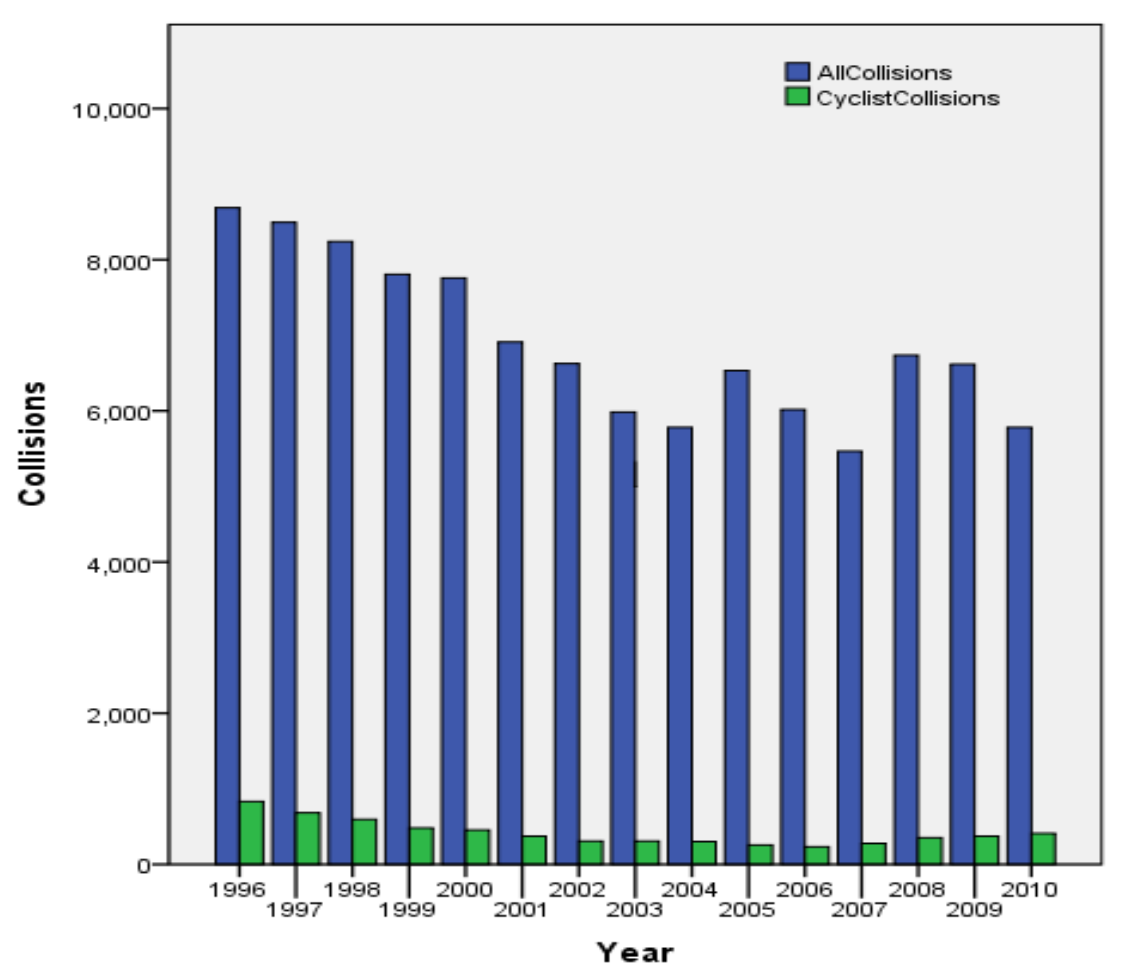

Figure 2. Cyclist Casualties 1996-2010.

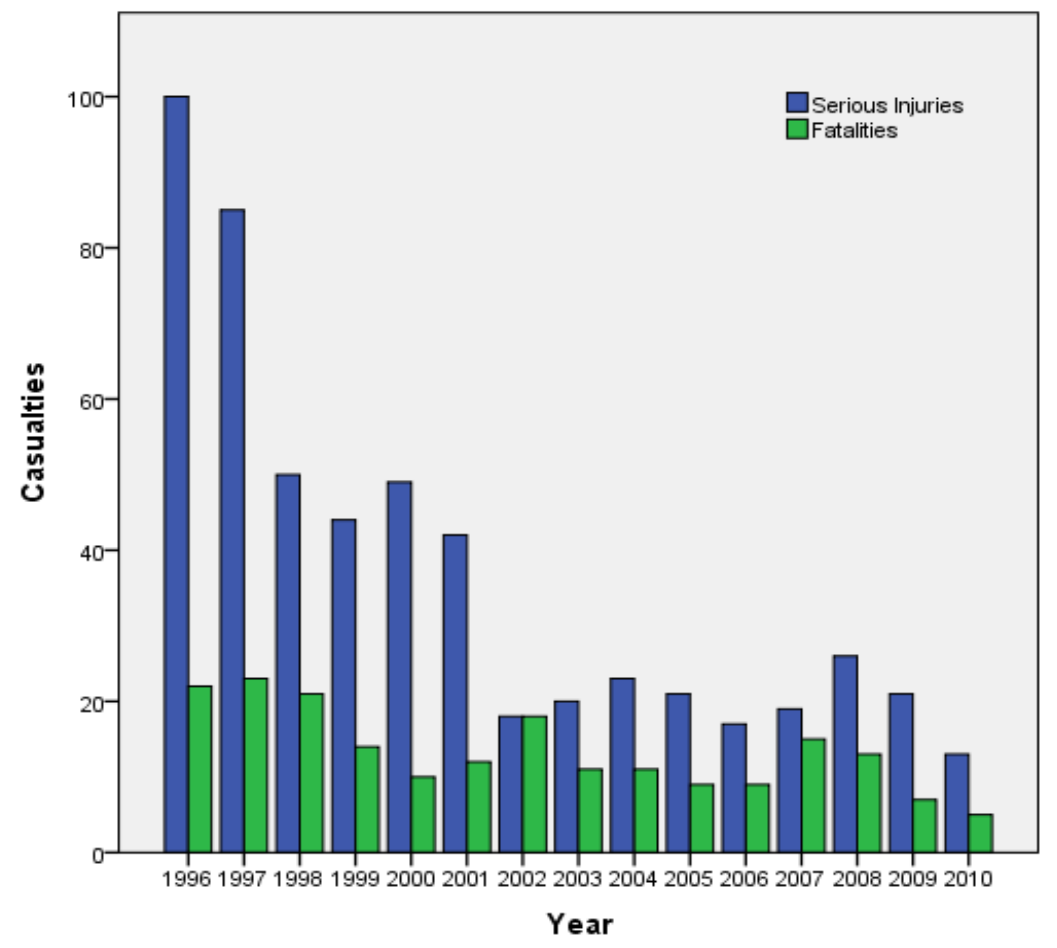




\section{Tables to Include in Annex (Numbered A1 to A7)}

Table A1. Trends in total and cyclist collisions - 1996-2010.

\begin{tabular}{|l|c|c|c|c|c|c|c|c|}
\hline \multirow{2}{*}{ Year } & \multicolumn{4}{|c|}{ All Collisions } & \multicolumn{4}{c|}{ Cyclist Collisions } \\
\cline { 2 - 9 } & Total & Fatal & Serious & Minor & Total & Fatal & Serious & Minor \\
\hline 1996 & 8686 & 415 & 1651 & 6620 & 833 & 24 & 104 & 705 \\
& $100 \%$ & $5 \%$ & $19 \%$ & $76 \%$ & $100 \%$ & $3 \%$ & $12 \%$ & $85 \%$ \\
\hline 1997 & 8496 & 424 & 1544 & 6528 & 683 & 26 & 90 & 567 \\
& $100 \%$ & $5 \%$ & $18 \%$ & $77 \%$ & $100 \%$ & $4 \%$ & $13 \%$ & $83 \%$ \\
\hline 1998 & 8239 & 408 & 1345 & 6486 & 596 & 21 & 52 & 523 \\
& $100 \%$ & $5 \%$ & $16 \%$ & $79 \%$ & $100 \%$ & $4 \%$ & $9 \%$ & $88 \%$ \\
\hline 1999 & 7807 & 374 & 1302 & 6131 & 481 & 14 & 46 & 421 \\
& $100 \%$ & $5 \%$ & $17 \%$ & $79 \%$ & $100 \%$ & $3 \%$ & $10 \%$ & $88 \%$ \\
\hline 2000 & 7757 & 362 & 1189 & 6206 & 455 & 10 & 50 & 395 \\
& $100 \%$ & $5 \%$ & $15 \%$ & $80 \%$ & $100 \%$ & $2 \%$ & $11 \%$ & $87 \%$ \\
\hline 2001 & 6909 & 360 & 1034 & 5515 & 374 & 12 & 43 & 319 \\
& $100 \%$ & $5 \%$ & $15 \%$ & $80 \%$ & $100 \%$ & $3 \%$ & $11 \%$ & $85 \%$ \\
\hline 2002 & 6625 & 346 & 827 & 5452 & 306 & 19 & 19 & 268 \\
& $100 \%$ & $5 \%$ & $12 \%$ & $82 \%$ & $100 \%$ & $6 \%$ & $6 \%$ & $88 \%$ \\
& & & & & & & &
\end{tabular}




\begin{tabular}{|l|c|c|c|c|c|c|c|c|}
\hline 2003 & 5985 & 301 & 796 & 4888 & 307 & 11 & 21 & 275 \\
& $100 \%$ & $5 \%$ & $13 \%$ & $82 \%$ & $100 \%$ & $4 \%$ & $7 \%$ & $90 \%$ \\
\hline 2004 & 5781 & 334 & 662 & 4785 & 301 & 11 & 23 & 267 \\
& $100 \%$ & $6 \%$ & $11 \%$ & $83 \%$ & $100 \%$ & $4 \%$ & $8 \%$ & $89 \%$ \\
\hline 2005 & 6533 & 360 & 787 & 5386 & 256 & 10 & 24 & 222 \\
& $100 \%$ & $6 \%$ & $12 \%$ & $82 \%$ & $100 \%$ & $4 \%$ & $9 \%$ & $87 \%$ \\
\hline 2006 & 6018 & 321 & 653 & 5044 & 232 & 9 & 18 & 205 \\
& $100 \%$ & $5 \%$ & $11 \%$ & $84 \%$ & $100 \%$ & $4 \%$ & $8 \%$ & $88 \%$ \\
\hline 2007 & 5467 & 309 & 618 & 4540 & 277 & 15 & 22 & 240 \\
& $100 \%$ & $6 \%$ & $11 \%$ & $83 \%$ & $100 \%$ & $5 \%$ & $8 \%$ & $87 \%$ \\
\hline 2008 & 6736 & 254 & 613 & 5869 & 351 & 13 & 29 & 309 \\
& $100 \%$ & $4 \%$ & $9 \%$ & $87 \%$ & $100 \%$ & $4 \%$ & $8 \%$ & $88 \%$ \\
\hline 2009 & 6615 & 220 & 463 & 5932 & 374 & 7 & 21 & 346 \\
& $100 \%$ & $3 \%$ & $7 \%$ & $90 \%$ & $100 \%$ & $2 \%$ & $6 \%$ & $93 \%$ \\
\hline
\end{tabular}


Table A2. All Collisions and Collisions Involving Cyclists, 1996-2010

\begin{tabular}{|c|c|c|c|c|c|c|}
\hline \multirow{2}{*}{\multicolumn{2}{|c|}{ Collisions }} & \multicolumn{2}{|c|}{ Cycling } & \multicolumn{2}{|c|}{ All Collisions } & \multirow{2}{*}{$\begin{array}{c}\text { Cycling } \\
\text { Share (\%) }\end{array}$} \\
\hline & & No. & $\%$ & No. & $\%$ & \\
\hline \multicolumn{2}{|l|}{ All } & 6,234 & 100 & 103,434 & 100 & 6.0 \\
\hline \multicolumn{7}{|l|}{ of which: } \\
\hline & Fatal & 207 & 3.3 & 4,973 & 4.8 & 4.2 \\
\hline & Serious & 577 & 9.3 & 13,893 & 13.4 & 4.1 \\
\hline & Minor & 5,450 & 87.4 & 84,568 & 81.8 & 6.4 \\
\hline \multicolumn{7}{|c|}{ Road and Environment } \\
\hline & Dry & 4,909 & 79.8 & 73,385 & 71.5 & 6.7 \\
\hline & Good visibility & 4,366 & 70.4 & 60,171 & 58.4 & 7.3 \\
\hline & Straight & 4,189 & 70.0 & 62,593 & 62.2 & 6.7 \\
\hline & 2-lane & 4,454 & 83.5 & 81,534 & 87.4 & 5.5 \\
\hline & At Junction & 3,213 & 51.5 & 36,671 & 35.5 & 8.8 \\
\hline \multicolumn{7}{|c|}{ Personal and Trip factors } \\
\hline \multirow[t]{3}{*}{ Trip Purpose: } & Work & 913 & 25.3 & 31,930 & 29.4 & 2.9 \\
\hline & School & 240 & 6.6 & 830 & 0.8 & 28.9 \\
\hline & Leisure & 2328 & 64.5 & 65,716 & 65.3 & 3.5 \\
\hline \multirow[t]{4}{*}{ Season: } & Winter & 1,299 & 20.8 & 24,426 & 23.6 & 5.3 \\
\hline & Spring & 1,487 & 23.9 & 25,283 & 24.4 & 5.8 \\
\hline & Summer & 1,753 & 28.1 & 26,405 & 25.5 & 6.6 \\
\hline & Autumn & 1,696 & 27.3 & 27,320 & 26.4 & 6.2 \\
\hline \multirow[t]{2}{*}{ Day: } & Weekend & 1,155 & 18.5 & 30,829 & 29.8 & 3.7 \\
\hline & Weekday & 5,076 & 81.5 & 72,605 & 70.2 & 7.0 \\
\hline \multirow[t]{4}{*}{ Time: } & Morning Peak & 1378 & 22.2 & 16,968 & 16.5 & 8.1 \\
\hline & Day & 1720 & 27.8 & 27,479 & 26.7 & 6.3 \\
\hline & Evening Peak & 2419 & 39.0 & 33,973 & 33.0 & 7.1 \\
\hline & Night & 674 & 10.9 & 24,426 & 23.8 & 2.8 \\
\hline \multicolumn{2}{|c|}{ Knows location } & 4265 & 83.4 & 69,126 & 87.6 & 6.2 \\
\hline
\end{tabular}


Table A3. Cycle Collision Severity.

\begin{tabular}{|c|c|c|c|c|}
\hline \multirow{2}{*}{ Broad factors } & \multirow{2}{*}{ Specific } & \multicolumn{3}{|c|}{ Cyclist Collisions } \\
\hline & & Total & Serious & Share\% \\
\hline \multicolumn{2}{|l|}{ All } & 6234 & 784 & 12.6 \\
\hline \multirow{22}{*}{$\begin{array}{l}\text { Road and } \\
\text { Environmental } \\
\text { factors }\end{array}$} & Dry & 4909 & 658 & 13.4 \\
\hline & Not Dry & 901 & 97 & 10.8 \\
\hline & Daylight & 4366 & 552 & 12.6 \\
\hline & Dark-no lighting & 150 & 64 & $42.7^{*}$ \\
\hline & At Junction & 3213 & 312 & 9.7 \\
\hline & Not at Junction & 3021 & 472 & $15.6^{*}$ \\
\hline & at $X$ road & 788 & 85 & 10.8 \\
\hline & at $\mathrm{Y}$ junction & 143 & 19 & 13.3 \\
\hline & at T Junctions & 1787 & 169 & 9.4 \\
\hline & at Roundabout & 328 & 19 & 5.8 \\
\hline & Complex Junctions & 167 & 20 & 12.0 \\
\hline & 2 Lane Road & 4454 & 632 & 14.2 \\
\hline & One Way & 597 & 45 & 7.5 \\
\hline & Straight & 3822 & 632 & 14.2 \\
\hline & Bend & 552 & 45 & 7.5 \\
\hline & Familiar with location & 3824 & 541 & 14.1 \\
\hline & Unfamiliar with Location & 143 & 41 & $28.7^{*}$ \\
\hline & $30 \mathrm{Km} / \mathrm{hr}$ & 72 & 4 & 5.3 \\
\hline & $50 \mathrm{Km} / \mathrm{hr}$ & 4431 & 422 & 8.7 \\
\hline & $60 \mathrm{Km} / \mathrm{hr}$ & 269 & 35 & 11.5 \\
\hline & $80 \mathrm{Km} / \mathrm{hr}$ & 189 & 53 & $21.9 *$ \\
\hline & $100 \mathrm{Km} / \mathrm{hr}$ & 429 & 251 & $36.5^{* *}$ \\
\hline \multirow{17}{*}{$\begin{array}{l}\text { Personal and } \\
\text { Trip Factors }\end{array}$} & Weekday & 5079 & 588 & 11.6 \\
\hline & Weekend & 1155 & 196 & 17.0 \\
\hline & Night time & 674 & 95 & 14.1 \\
\hline & Morning Peak & 1378 & 127 & 9.2 \\
\hline & Day & 1720 & 236 & 13.7 \\
\hline & Evening Peak & 2419 & 322 & 13.3 \\
\hline & Under14 & 985 & 184 & $18.7^{*}$ \\
\hline & $15-24$ & 1302 & 155 & 11.9 \\
\hline & $25-34$ & 1178 & 105 & 8.9 \\
\hline & $35-44$ & 632 & 64 & 10.1 \\
\hline & $45-54$ & 440 & 62 & 14.1 \\
\hline & $55-64$ & 315 & 62 & 19.7 \\
\hline & 65and over & 216 & 56 & $25.9 * *$ \\
\hline & With Car & 5073 & 517 & 12.8 \\
\hline & With Truck / bus & 545 & 141 & 13.1 \\
\hline & Male & 4418 & 566 & 12.8 \\
\hline & Female & 1336 & 175 & 13.1 \\
\hline
\end{tabular}

(1) Percentages that are significantly different statistically from the population means (12.6 on the first line above) are shown with an * if the difference is significant at the $5 \%$ level, and with $* *$ if it is significant at the $1 \%$ level. The test statistic used was $\left(\mathbf{p}-\mathbf{p}_{0}\right) \mathbf{n}^{1 / 2} /(\mathbf{p q})^{1 / 2}$ where $\mathbf{p}$ and $\mathbf{p}_{0}$ are the observed and population percentages, $\mathbf{q}=\mathbf{1 - p}$ and $\mathbf{n}$ is the observed number of collisions in the category concerned. 
Table A4. Logistic Regression; Definition of Variables included

\begin{tabular}{|c|c|c|c|c|}
\hline Variable & Type & Definition & Values & Other values \\
\hline Speed & $\begin{array}{l}\text { Discrete Values, } \\
\text { Independent }\end{array}$ & Road Speed limit & $30,50,60,80,100,120$ & none \\
\hline Dark Roads & $\begin{array}{l}\text { Dichotomous, } \\
\text { Independent }\end{array}$ & $\begin{array}{l}\text { Collision occurred on } \\
\text { unlit road after dark }\end{array}$ & 1 & 0 \\
\hline Older Cyclists & $\begin{array}{l}\text { Dichotomous, } \\
\text { Independent }\end{array}$ & Age 55 or over & 1 & 0 \\
\hline Young Cyclists & $\begin{array}{l}\text { Dichotomous, } \\
\text { Independent }\end{array}$ & Age less than 15 & 1 & 0 \\
\hline $\begin{array}{l}\text { Young Driver } \\
\text { (crash } \\
\text { opponent) }\end{array}$ & $\begin{array}{l}\text { Dichotomous, } \\
\text { Independent }\end{array}$ & $\begin{array}{l}\text { Male Driver under } 25 \\
\text { years }\end{array}$ & 1 & 0 \\
\hline Serious Injury & $\begin{array}{l}\text { Dichotomous, } \\
\text { Dependent }\end{array}$ & $\begin{array}{l}\text { Police recorded } \\
\text { serious injury }\end{array}$ & 1 & 0 \\
\hline
\end{tabular}

Table A5. Hospitalised Cyclists by type of accident and whether traffic or not 2005-2011

\begin{tabular}{|l|c|c|c|}
\hline \multicolumn{1}{|c|}{ Type of Collision } & Traffic Accident & $\begin{array}{c}\text { Non-traffic accident or } \\
\text { unspecified }\end{array}$ & Total \\
\hline $\begin{array}{l}\text { Pedestrian, cyclist or } \\
\text { motor cycle }\end{array}$ & 59 & 95 & 154 \\
\hline Vehicle & 589 & 122 & 711 \\
\hline Object & 53 & 151 & 204 \\
\hline Non Collision (falls) & 944 & 3167 & 4111 \\
\hline Other/NS & 659 & 722 & 1385 \\
\hline Total & $\mathbf{2 3 0 4}$ & $\mathbf{4 2 6 1}$ & $\mathbf{6 5 6 5}$ \\
\hline
\end{tabular}

Source: HIPE data, ESRI. 
Table A6. Length of Stay for Cyclists by type of accident, 2005-2011.

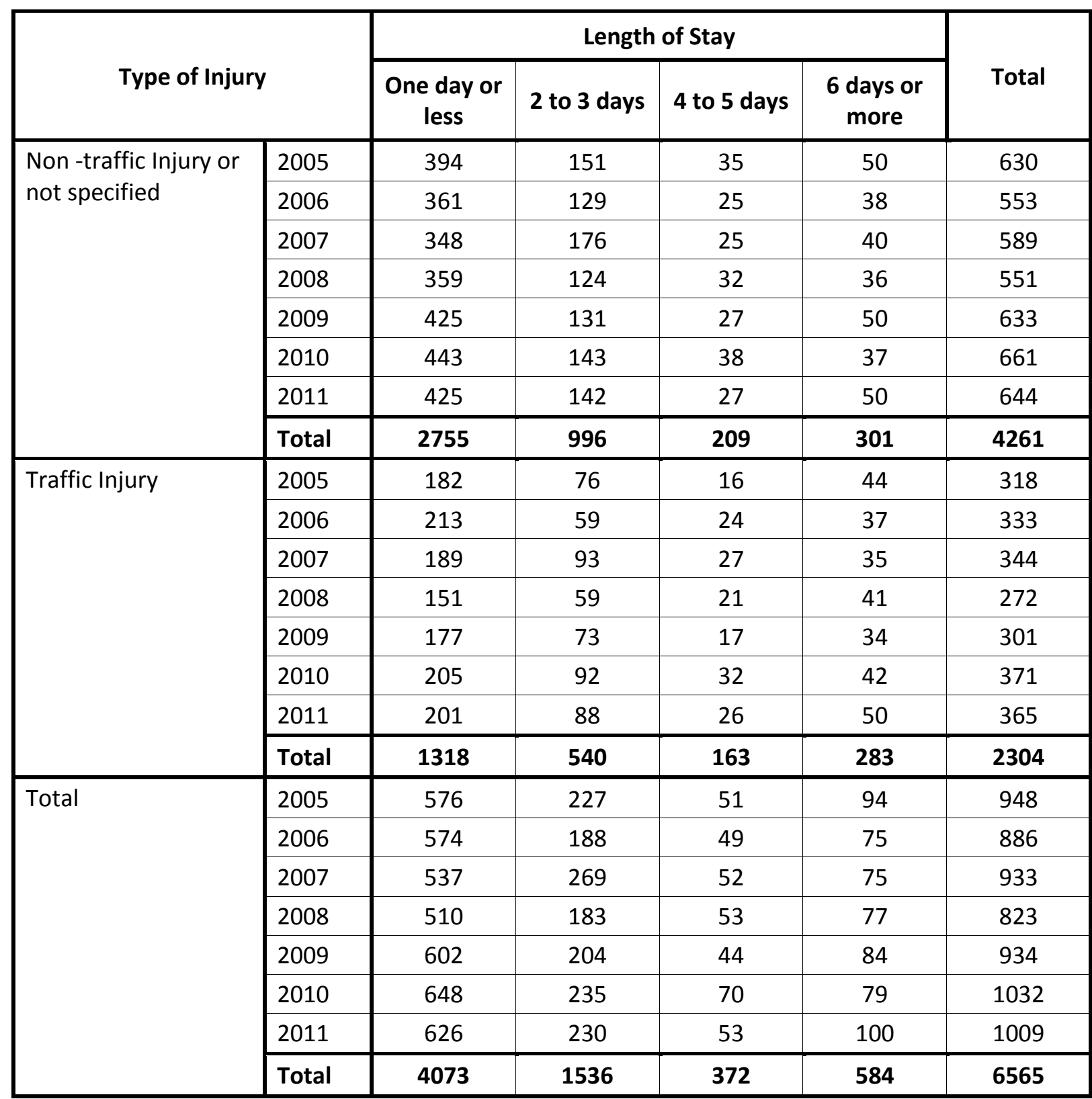

Source: HIPE data, ESRI. 
Table A7. Hospitalised Cyclists by Sex Age and Type of Injury 2005-2011.

\begin{tabular}{|c|c|c|c|c|c|}
\hline \multirow{2}{*}{\multicolumn{3}{|c|}{ Type of Injury }} & \multicolumn{2}{|c|}{ Sex } & \multirow{3}{*}{$\frac{\text { Total }}{2,589}$} \\
\hline & & & \multirow{2}{*}{$\frac{\text { Male }}{1,765}$} & \multirow{2}{*}{$\begin{array}{r}\text { Female } \\
824\end{array}$} & \\
\hline Non -traffic Injury or & Age Group & $0-14$ & & & \\
\hline \multirow[t]{7}{*}{ not specified } & & $15-24$ & 376 & 77 & 453 \\
\hline & & $25-34$ & 276 & 83 & 359 \\
\hline & & $35-44$ & 214 & 43 & 257 \\
\hline & & $45-54$ & 188 & 67 & 255 \\
\hline & & $55-64$ & 132 & 55 & 187 \\
\hline & & 65 and over & 120 & 41 & 161 \\
\hline & Total & & 3,071 & 1190 & 4,261 \\
\hline \multirow[t]{8}{*}{ Traffic Injury } & Age Group & $0-14$ & 695 & 304 & 999 \\
\hline & & $15-24$ & 273 & 39 & 312 \\
\hline & & $25-34$ & 210 & 81 & 291 \\
\hline & & $35-44$ & 197 & 41 & 238 \\
\hline & & $45-54$ & 140 & 56 & 196 \\
\hline & & $55-64$ & 95 & 55 & 150 \\
\hline & & 65 and over & 90 & 28 & 118 \\
\hline & Total & & 1,700 & 604 & 2,304 \\
\hline \multirow[t]{8}{*}{ Total } & Age Group & $0-14$ & 2,460 & 1,128 & 3,588 \\
\hline & & $15-24$ & 649 & 116 & 765 \\
\hline & & $25-34$ & 486 & 164 & 650 \\
\hline & & $35-44$ & 411 & 84 & 495 \\
\hline & & $45-54$ & 328 & 123 & 451 \\
\hline & & $55-64$ & 227 & 110 & 337 \\
\hline & & 65 and over & 210 & 69 & 279 \\
\hline & Total & & 4,771 & 1,794 & 6,565 \\
\hline
\end{tabular}

